\title{
Tracheostomy in Adult Intensive Care Unit: An ISCCM Expert Panel Practice Recommendations
}

Sachin Gupta ${ }^{1}$, Subhal Dixit ${ }^{2}$, Dhruva Choudhry ${ }^{3}$, Deepak Govil ${ }^{4}$, Rajesh Chandra Mishra ${ }^{5}$, Srinivas Samavedam ${ }^{6}$, Kapil Zirpe $^{7}$, Shrikanth Srinivasan ${ }^{8}$, Zubair Mohamed ${ }^{9}$, Venkatesha Gupta KV ${ }^{10}$, Jaya Wanchoo ${ }^{11}$, Nilanchal Chakrabortty ${ }^{12}$, Sushma Gurav ${ }^{13}$

\begin{abstract}
Background and Aim: Critically ill patients on mechanical ventilation undergo tracheostomy to facilitate weaning. The practice in India may be different from the rest of the world and therefore, in order to understand this, ISCCM conducted a multicentric observational study “DIlatational percutaneous vs Surgical tracheostomy in intEnsive Care uniT: A practice pattern observational multicenter study (DISSECT Study)" followed by an ISCCM Expert Panel committee meeting to formulate Practice recommendations pertinent to Indian ICUs.

Materials and methods: All existing International guidelines on the topic, various randomized controlled trials, meta-analysis, systematic reviews, retrospective studies were taken into account to formulate the guidelines. Wherever Indian data was not available, international data was analysed. A modified Grade system was followed for grading the recommendation.

Results: After analyzing the entire available data, the recommendations were made by the grading system agreed by the Expert Panel. The recommendations took into account the indications and contraindications of tracheostomy; effect of timing of tracheostomy on incidence of ventilator associated pneumonia, ICU length of stay, ventilator free days \& Mortality; comparison of surgical and percutaneous dilatational tracheostomy (PDT) in terms of incidence of complications and cost to the patient; Comparison of various techniques of PDT; Use of fiberoptic bronchoscope and ultrasound in PDT; experience of the operator and qualification; certain special conditions like coagulopathy and morbid obesity.

Conclusion: This document presents the first Indian recommendations on tracheostomy in adult critically ill patients based on the practices of the country. These guidelines are expected to improve the safety and extend the indications of tracheostomy in critically ill patients. Keywords: Coagulopathy, Obesity, Percutaneous dilatational, Recommendations, Tracheostomy, Ultrasound.

Indian Journal of Critical Care Medicine (2020): 10.5005/jp-journals-10071-G23184
\end{abstract}

\section{INTRODUCTION}

Although tracheostomy is one of the most commonly performed procedure in Intensive care unit (ICU), ${ }^{1}$ it is also one of the most diverse with respect to the choice of technique (surgical vs percutaneous). Similarly, there are lot of controversies regarding the indications, contraindications and timing of tracheostomy and these add to the complexity of decision making when faced with a mechanically ventilated patients requiring tracheostomy. ${ }^{2}$

The purpose of this document is to produce practice based recommendations which are relevant in the Indian ICUs based on the available scientific evidence from within the country and also from international literature. The compilation of the recommendation was done at the consensus meeting of a group of expert intensivists from across the country and also based on the information obtained from the multicentric observational study: DISSECT study ${ }^{3}$ (Dllatational percutaneous vs Surgical tracheoStomy in intEnsive Care uniT: A Practice Pattern Observational Multicenter Study). The recommendations of this document are applicable only to individuals who are above 18 years of age.

\section{Definitions}

Tracheostomy means creating an opening in the trachea for the passage of the tube through which patients can be ventilated or the patient can breathe spontaneously.

Surgical Tracheostomy (ST) involves placement of a tracheostomy tube in the trachea after performing dissection of
Corresponding Author: Sachin Gupta, Department of Critical Care, Narayana Superspeciality Hospital, Critical Care Medicine, Gurgaon, Haryana, India, Phone: 9873240734, e-mail: dr_sachin78@yahoo.co.in

How to cite this article: Gupta S, Dixit S, Choudhry D, Govil D, Mishra RC, Samavedam S, Tracheostomy in Adult Intensive Care Unit: An ISCCM Expert Panel Practice Recommendations. Indian J Crit Care Med 2020;24(Suppl 1):S31-S42.

Source of support: Nil

Conflict of interest: None

pre-tracheal fascia and creating an opening in the trachea under direct vision. It can be performed both in ICU or operation theatre (OT).

Percutaneous Dilatational Tracheostomy (PDT) is mostly performed as a bedside procedure where tracheostomy tube is placed in the trachea after creating an opening in the trachea by blunt dissection of pre-tracheal soft tissue with the help of Seldinger technique.

\section{Methods}

\section{The Expert Panel}

The guidelines were developed by an Expert Panel of Members of Indian Society of Critical Care Medicine (ISCCM) under the chairmanship of the President of ISCCM. The panel comprised of senior intensivists, experts in the field and five principal

(c) The Author(s). 2020 Open Access This article is distributed under the terms of the Creative Commons Attribution 4.0 International License (https://creativecommons. org/licenses/by-nc/4.0/), which permits unrestricted use, distribution, and non-commercial reproduction in any medium, provided you give appropriate credit to the original author(s) and the source, provide a link to the Creative Commons license, and indicate if changes were made. The Creative Commons Public Domain Dedication waiver (http://creativecommons.org/publicdomain/zero/1.0/) applies to the data made available in this article, unless otherwise stated. 
investigators who contributed maximally to the DISSECT study. The results of DISSECT study were taken as a reflection of the tracheostomy practices in India and the guidelines were formulated keeping in mind the available resources and the practice trends.

\section{Literature Search and Review}

A PUBMED search was performed with various keywords like "tracheostomy", "tracheotomy", "percutaneous", "surgical", "open tracheostomy", "indications", "complications", "mortality", "length of stay", "bronchoscopy", "ultrasound", "cost", "obese", "morbidly obese", "coagulopathy" which were relevant to various questions framed for the guideline. None of the studies or case reports or meta-analysis were rejected but they were graded as per the strength of the article. Cross references from the relevant articles and all guidelines on the topic were also reviewed.

\section{Literature Grading and Recommendations}

We used the modified grade system to classify the quality of evidence and the strength of recommendations (Table 1). The draft document that was formulated was reviewed by the expert panel and all suggestions were incorporated in the final draft after approval through consensus. The questions developed for the guidelines used the acronym PICO: ${ }^{4} \mathrm{P}$, patients; I, intervention; $\mathrm{C}$, comparison; and $\mathrm{O}$, outcome.

\section{Scope of Guidelines}

The scope of this document includes the indications of tracheostomy in ICU, the choice between surgical versus percutaneous tracheostomy, guidance used during tracheostomy, the immediate complications of tracheostomy, the weaning time frame after tracheostomy and the average cost of this procedure in India. They also cover tracheostomy in special situations like morbidly obese and coagulopathic patients. These guidelines are only for adult patients ( $>18$ years).

\section{TRACHEOSTOMY - INDICATIONS AND CONTRAINDICATIONS}

\section{Are there any Absolute Contraindications to Tracheostomy?}

Traditionally, certain contraindications for performing tracheostomy have been described in the literature and they were more pertinent to PDT. But the literature also emphasizes that as the experience of the user with the technique increases, ${ }^{5}$ these contraindications become relative and hence, the risk associated with these conditions also decreases. ${ }^{6}$

Morbid obesity was earlier considered as a contraindication for performing PDT due to difficult anatomy. However, recent studies have shown that PDT is equally safe as compared to ST in this subset of patients. ${ }^{7}$

Coagulopathy was also considered as a contraindication for performing tracheostomy and its prior correction was deemed necessary before the procedure. Although now there is ample literature demonstrating that with increased skill of the operator, coagulopathy is a relative contraindication and the procedure can be performed safely. ${ }^{8,9}$ A recent observational study involving data of tracheostomy in 652 patients with and without coagulopathy
Table 1: Modified grade system

\begin{tabular}{|c|c|}
\hline Quality of Evidence & Level \\
\hline $\begin{array}{l}\text { Evidence from } \geq 1 \text { good quality and well-con- } \\
\text { structed randomized control trial(s) or meta- } \\
\text { analysis of RCT's }\end{array}$ & 1 \\
\hline $\begin{array}{l}\text { Evidence from at least } 1 \mathrm{RCT} \text { of moderate quality, } \\
\text { or well-designed clinical trial without randomiza- } \\
\text { tion; or from cohort or case-controlled studies. }\end{array}$ & 2 \\
\hline $\begin{array}{l}\text { Evidence from descriptive studies, or reports } \\
\text { of expert committees, or opinion or respected } \\
\text { authorities based on clinical experience }\end{array}$ & 3 \\
\hline $\begin{array}{l}\text { Not backed by sufficient evidence; however, a } \\
\text { consensus reached by the working group, based } \\
\text { on clinical experience and expertise }\end{array}$ & $\begin{array}{l}\text { Useful } \\
\text { Practice Point } \\
\text { (UPP) }\end{array}$ \\
\hline Strength of Recommendations & Grade \\
\hline $\begin{array}{l}\text { Strong Recommendations to do (or not to do) } \\
\text { where the benefits clearly outweigh the risk (or } \\
\text { vice versa) for most, if not all patients }\end{array}$ & $A$ \\
\hline $\begin{array}{l}\text { Weak Recommendations, where benefits and risk } \\
\text { are more closely balanced or are more uncertain }\end{array}$ & B \\
\hline
\end{tabular}

concluded that PDT can be safely performed in patients with altered coagulation status with no increase in complications. ${ }^{10}$

In the recent DISSECT study, ${ }^{3}$ the most common reason for performing a surgical tracheostomy was altered neck anatomy like short neck or thick neck or obese patients. Other reasons were coagulopathy and in few cases, the admitting physician was not confident on performing PDT.

The common indications ${ }^{11}$ of tracheostomy in ICU are:

- Prolonged ventilation

- Weaning from ventilator support

- Tracheobronchial toileting and secretion management

- Upper airway obstruction

- Permanent airway control in malignancies or trauma or neurological conditions

The contraindications for tracheostomy are:

Absolute

- Informed consent not available

- Infection at the site of tracheostomy

Relative

- Coagulopathy

- $\quad$ Altered neck anatomy like thyroid mass/swelling

- Unstable cervical spine

- Morbidly obesity

- Patients on ventilator support with high PEEP

\section{Recommendation}

There are no absolute contraindications to tracheostomy except refusal of consent and infections at the site of planned procedure (3B)

\section{TIMING OF TRACHEOSTOMY}

For the purpose of the document, ISCCM Expert Panel has decided to define Early Tracheostomy as within or equal to 7 days of ventilation and late tracheostomy as any tracheostomy performed beyond 7 days. 


\section{Does early tracheostomy reduce the incidence of ventilator associated pneumonia (VAP) as compared to late tracheostomy?}

Intubated patients are at an increased risk of VAP due to microaspiration of oropharyngeal secretions. The question that whether early tracheostomy (ET) confers advantage in prevention of VAP is controversial. First the definition of ET has been different in various RCTs ranging from day 1 to day 4 , to upto day 10. Most of the literature takes ET as the procedure performed upto day 7 of intubation.

A meta-analysis ${ }^{12}$ involving four RCTs $s^{13-16}$ in 2005 found no difference in hospital-acquired pneumonia in both the groups (relative risk $0.90,95 \% \mathrm{Cl} 0.66-1.21$ ). A large $\mathrm{RCT}^{17}$ conducted in Italian ICU in 2010 involving almost 600 patients also did not find any statistically significant difference in VAP incidence in early vs late tracheostomy $(14 \%$ vs $21 \%, p=0.07)$. Another meta-analysis ${ }^{16}$ involving $7 \mathrm{RCTs}^{13-16,19-21}$ conducted in 2011 involving 1044 patients did not find any difference in VAP rates in critically ill patients undergoing early tracheostomy (relative risk 0.94, 95\% CI 0.77-1.15). The limitation of all these RCTs included in meta-analysis was the heterogeneity of the definition of VAP. Some studies followed the CPIS (Clinical Pulmonary Infection Score) scoring system whereas others measured VAP as per the definition of patients on ventilator for $>48$ hours.

In the $\mathrm{RCT}^{20}$ carried out in a mixed medical surgical ICU, it was found that the ICU-acquired pneumonia curves did not differ between the groups $[P=0.94 ; \mathrm{HR}=0.98(95 \% \mathrm{Cl}: 0.60-1.62)]$.

In a recent meta-analysis ${ }^{22}$ of six observational studies involving 2037 patients, it was found that there was no statistically significant difference in the VAP prevalence rates between early and the late tracheostomy groups $(11.6 \%$ vs $11 \%$, odds ratio $0.71,95 \% \mathrm{Cl}$ $0.48-1.04, p=0.08) .{ }^{23-25}$ In the recently concluded DISSECT study, the prevalence of early tracheostomy was much higher than late tracheostomy $(73.7 \%$ vs $26.3 \%, p<0.05)$.

\section{Recommendation}

- The incidence of VAP does not change with early (within 7 days of ventilation) or late tracheostomy (1 A)

- Early Tracheostomy should not be used as a strategy to reduce the incidence of VAP (1 A)

Does early tracheostomy reduce the ICU length of stay (LOS) as compared to late tracheostomy?

In the meta-analysis conducted in $2005^{12}$ involving around 226 patients from two RCTs ${ }^{13,14}$ concluded that early tracheostomy reduces the ICU length of stay ( -15.3 days, -24.6 days to -6.1 days, $P=0.001)$. They also pointed out that there is lot of heterogeneity in various RCTs regarding the ICU LOS. In the meta-analysis published by Wang et al $^{18}$ in 2011 which included 1044 patients from seven RCTs, there was a trend towards reduced ICU LOS but it did not meet statistical significance (Weighted Mean Difference, -6.93 days; $95 \% \mathrm{Cl},-16.50-2.63 ; P=.16)$. In a recent meta-analysis of $2016,{ }^{26}$ nine studies comprising of 2040 patients were enrolled out of which 5 studies discussed the relationship of early tracheostomy with ICU LOS and they concluded that ICU LOS does not reduce with early tracheostomy, although the trend was towards reducing the LOS but not meeting statistical significance (WMD $=-7.57$ days; $95 \% \mathrm{Cl}$ $=-15.42$ to 0.29 days; $P=0.06$ ). The studies were heterogenous in nature and not high quality studies.
Apart from these, there are various RCTs conducted in various subsets of patients which have concluded that early tracheostomy leads to reduced ICU LOS. In the RCT by Tong et $\mathrm{al}^{25}$ it was found that early tracheostomy reduced ICU LOS by $33 \%$. Similarly, in the RCT conducted by Mohamed et al, ${ }^{27}$ the ICU LOS was shorter in the early PDT group as compared to late PDT group (32.2 \pm 10.5$)$ vs (20.6 \pm 13 days; $p=0.004)$. In the RCT conducted by Terragni et al, ${ }^{17}$ the ICU free days were significantly higher in the early tracheostomy group as compared to the late group.

In the retrospective study by Zirpe et $\mathrm{al}^{28}$ conducted in neurointensive care unit, it was found that early tracheostomy results in shorter stay in ICU (mean, 28.8 vs. 34.37 days, $P=0.019$ ).

\section{Recommendation}

Early tracheostomy may result in reduction of ICU length of stay as compared to late tracheostomy (1A)

\section{Does early tracheostomy increase the ventilator free days (VFD) as compared to late tracheostomy?}

There are many RCTs and meta-analysis supporting the practice of early tracheostomy to increase the ventilator free days (VFD) as compared to late tracheostomy group. In a retrospective analysis of surgical ICU patients, ${ }^{23}$ the authors found that early tracheostomy ( $<7$ days of ventilation) increases the VFD (12.2 \pm 0.9 vs $21.9 \pm 1.3$ days). In the TracMan trial ${ }^{29} 909$ patients were enrolled and divided into early and late tracheostomy groups. The patients in the early tracheostomy group had reduced need of respiratory support as compared to late tracheostomy group, although it did not meet statistical significance (mean 13.6 days vs 15.2 days, $p=0.06$ ). Devarajan et $\mathrm{al}^{30}$ in their retrospective review of patients who underwent tracheostomy after cardiac surgery showed that early tracheostomy group (within 10 days of ventilation) had shorter intubation time by 5.5 days as compared to late tracheostomy group $(p=0.011)$. In a meta-analysis ${ }^{20}$ of four observational trials, ${ }^{23,24,25,31}$ the early tracheostomy group had shorter duration of mechanical ventilation as compared to delayed tracheostomy group (mean difference $-10.04 \mathrm{~d}, 95 \% \mathrm{Cl}-15.15$ to $-4.92, p=0.001$ ).

In a systematic review by Koji et al, ${ }^{32}$ five RCTs $s^{17,19,21,33,34}$ were studied for VFD and it was greater with early tracheostomy group (WMD 2.10, 0.44, $p<0.01$ ). Contrary to the available literature, a meta-analysis ${ }^{36}$ which included nine studies ${ }^{15,16,19,20,21,29,34,36,37}$ (1623 patients) studying the relationship of duration of mechanical ventilation and timing of tracheostomy could not establish a statistical significance and concluded that early tracheostomy did not increase VFD [- 0.19 days (-1.13-0.75)]. A meta-analysis ${ }^{12}$ conducted in 2005 included 406 patients from 5 RCTs ${ }^{13-16}$ concluded that early tracheostomy significantly reduces the duration of mechanical ventilation (WMD 8.5 days). Similarly, the Cochrane review $^{38}$ conducted in 2015 included various studies ${ }^{13,17,21,34,37}$ of varying heterogeneity and on individual evaluation of these studies, the results were different in all studies although most studies pointing towards early tracheostomy reducing the duration of mechanical ventilation and increasing VFD.

The effect of early tracheostomy on VFD has been studied in neurointensive care in various RCTs and has shown that it significantly reduces the need for mechanical ventilation in patients with stroke or who have undergone decompressive craniectomy. ${ }^{39,40}$ The average reduction has ranged from 10-16 days. In two retrospective cohort studies ${ }^{41,42}$ one in Japan and the other in Taiwan, looked at VFD and early tracheostomy. It was found 
that early tracheostomy had a median of 10 days more ventilation free days as compared to late tracheostomy $(\mathrm{Cl}=1.06-2.38, \mathrm{p}=$ 0.027 ) in the Japan study whereas the MV duration was shorter in the other study $(35.2 \pm 21.4$ vs $46.6 \pm 18.8$ days, $\mathrm{P}=.001)$. A small RCT conducted ${ }^{43}$ on 67 adult ICU patients concluded that early tracheostomy reduced MV days significantly (7.91 \pm 4.937 SD vs $15.32 \pm 7.472 \mathrm{SD}, p=0.001$ )

\section{Recommendation:}

Early Tracheostomy may reduce the duration of mechanical ventilation and may result in more ventilator free days in critically ill patients (2 B)

\section{Does early tracheostomy reduce the mortality in critically ill patients as compared to late tracheostomy?}

There have been many RCTs and meta-analysis which has evaluated the relationship of timing of tracheostomy and mortality in critically ill patients. In the RCT by Blot et al, ${ }^{20}$ they found that mortality at day 28 was similar in early tracheostomy vs prolonged intubation (20\%; 95\%Cl: $11-31$ vs 24\%; Cl:15-36) and also at day 60 (27\%; $95 \%$ $\mathrm{Cl}: 17-39$ vs $24 \%$; $95 \% \mathrm{Cl}: 15-36)$. In another Italian $\mathrm{RCT}^{17}{ }^{17}$ the survival at 1 year was compared and in the early group, 72 patients $(50 \%$; $95 \% \mathrm{Cl}, 41 \%-61 \%)$ survived to 1 year compared with 63 patients (43\%; 95\% Cl, 34\%-52\%) in the late group ( $P=.25$ ). In the TracMan trial, ${ }^{29} 909$ patients were enrolled and mortality data was looked at 30 days and at 2 years. The all-cause mortality at 30 days in the early vs late tracheostomy was $30.8 \%(95 \% \mathrm{Cl}, 26.7 \%-35.2 \%)$ vs $31.5 \%$ (95\% Cl, 27.3\%-35.9\%) and absolute risk reduction was $0.7 \%$ (95\% Cl, 5.4\% to 6.7\%). The two-year mortality was $51.0 \%(95 \% \mathrm{Cl}$, 46.4\%-55.6\%) in the early and $53.7 \%(95 \% \mathrm{Cl}, 49.1 \%-58.3 \%)$ in the late group. In few other single centre RCTs, ${ }^{33,34,44,45}$ mortality at different time frames was compared with timing of tracheostomy and it was found that mortality at 60 days ( $p=0.949), 90$ days $(25.7 \%$ vs 29.9\%), 1 year ( $\mathrm{Cl} 95 \% 0.7$ [0.5-1.001], $p=0.051)$ and at hospital discharge ( $20 \%$ vs $22 \%$ ) had no difference. Similarly, a $\mathrm{RCT}^{31}$ in trauma patients revealed that early tracheostomy did not improve ICU and hospital mortality $(p=0.66)$.

The RCTs conducted in neurocritical care units had varying results. In patients with severe head injury, ${ }^{16}$ early tracheostomy did not change the mortality rates ( $38.7 \%$ vs $22.5 \%, p=0.27)$. In stroke patients, ${ }^{37}$ early tracheostomy decreased the ICU mortality $(10 \%$ vs $47 \%, p<0.01)$ as well as 6 -month mortality $(27 \%$ vs $60 \%, p=$ 0.02). Patients undergoing early tracheostomy after decompressive craniectomy ${ }^{39}$ had decreased hospital mortality ( $p=0.013$ ). Tracheostomy in cardiac surgical patients ${ }^{21,46}$ have not shown any benefit in terms of mortality at varying time frames whereas a retrospective review of prospective data conducted by Devarajan et al ${ }^{30}$ concluded that early tracheostomy is associated with reduced in hospital mortality ( $21.1 \%$ vs $40.4 \%, p=0.002)$

There have been atleast seven meta-analysis studying the relationship of timing of tracheostomy and mortality. Wang et $\mathrm{al}^{18}$ showed that early tracheostomy did not reduce the short term mortality (RR, $0.86 ; 95 \% \mathrm{Cl}, 0.65-1.13 ; P=0.28)$ as shown by seven trials $(N=1044)^{13,15-17,19-21}$ as well as long term mortality (RR, 0.86; 95\% Cl, 0.65-1.13; $P=0.28$ ) as shown by two trials $(N=$ 443). ${ }^{17,21}$ In another meta-analysis conducted by Meng et al, ${ }^{26}$ nine studies ${ }^{13,15,17,19-21,27,29,34}$ were included and the result was that early tracheostomy did not reduce the mortality [relative risk (RR) $=0.88 ; 95 \% \mathrm{Cl}=0.76-1.00 ; P=0.06]$. Szakmany et $\mathrm{al}^{35}$ conducted the meta-analysis by including 14 studies ${ }^{13,15-17,19-21,29,34,36,38,47,48}$ and found no difference in short term mortality (upto 60 days) between early and late tracheostomy (356/ 1180 [30.2\%] vs 391/1226 [31.9\%], RR: 0.93 [95\% Cl 0.83, 1.05). In the meta-analysis by Siempos et al ${ }^{49}$ enrolling 13 trials $(N=2434)^{13-17,19-21,29,34,37,45,47}$ concluded that the all-cause mortality was not lower in early tracheostomy as compared to late or no tracheostomy group (303 vs 345 deaths; OR $0.80,95 \% \mathrm{Cl} 0.59-1.09 ; p=0.16)$. Another meta-analysis by Liu et $\mathrm{al}^{50}$ concluded that there was no significant difference in hospital mortality (relative risk, $0.84 ; 95 \% \mathrm{Cl}, 0.67$ to $1.04 ; P=.11$ ), data was from 11 studies. ${ }^{13-15,17,19,29,34,48}$ The Cochrane database ${ }^{38}$ which included seven studies ${ }^{13,17,19,21,29,34,37}$ concluded that early tracheostomy reduced mortality as compared to delayed tracheostomy although the quality of evidence is moderate (47.1\%; 448/ 950 vs 53.2\%; 507/953,RR 0.83; $95 \% \mathrm{Cl} 0.70$ to $0.98 ; p$ $=0.03$ ). Another meta-analysis ${ }^{32}$ which enrolled 11 studies ${ }^{13,15,17,19-}$ $21,29,33,34,37,45$ also concluded that short term mortality is not affected by timing of tracheostomy.

The various retrospective studies $25,28,42,43,51,52$ conducted in different patient subsets also confirmed that the timing of tracheostomy does not reduce in hospital mortality.

\section{Recommendation}

- There is no difference in short term and long term mortality between early and late tracheostomy $(1 \mathrm{~A})$.

- Patients with stroke and those undergoing decompressive craniectomy may have reduced short term mortality with early tracheostomy (3 B).

\section{PDT vs ST}

\section{Does ST results in lower complications as compared to PDT in critically ill patients?}

The complications studied have been either divided into immediate and late complications or into serious, intermediate and minor complications. In the various RCTs, there was no difference in intermediate (desaturation, hypotension, posterior tracheal wall lesion, canula misplacement, switch to surgical technique) or serious (death, pneumothorax, pneumomediastinum) complications between ST \& PDT. Minor complications like hemorrhage, difficult tube placement was more in PDT group $(p=0.024) .{ }^{53}$ The other minor complications like cosmetic sequelae and postoperative infections have been higher with ST $(p=0.044) .{ }^{54}$ The skin incision size was smaller with PDT $(p<0.0001) .{ }^{55}$

The meta-analysis by Higgins et $\mathrm{al}^{56}$ which included 15 studies $(N=973),{ }^{55,57-70}$ showed no statistical significance for major complications between ST and PDT but the overall pattern of complications favored PDT $(0.75,0.56-1.00, p=0.05)$ in regards to incision scarring, wound infection and shortened procedure time. In another meta-analysis ${ }^{71}$ enrolling 14 studies, $^{57,58,61,63,64,66,68,70,72-}$

77 it was found that PDT causes less wound infection (pooled OR 0.20 [0.11 to 0.35 ]; $P<0.0001$ ). The same meta-analysis looked at data from 11 studies $^{59,61-63,68-70,60,72,78,74}$ and found that PDT decreases the procedure time (pooled OR 21.7 [22.7 to 0.7]; $P=$ 0.001). The meta-analysis by Delaney et $\mathrm{al}^{81}$ which included 15 studies ${ }^{55,57-63,65-70,80}$ concluded that the pooled odds ratio (OR) 
for wound infection was 0.28 (95\% confidence interval $(\mathrm{Cl}), 0.16$ to $0.49, p<0.0005)$, indicating a significant reduction with PDT compared to ST. Rest of the complications like bleeding and longterm complications including death were similar between PDT and ST. The meta-analysis performed by Putensen et al ${ }^{81}$ which included 9 RCTs ${ }^{58,55,60,61,63,65,66,70,74}$ also concluded that stomal infection was lower with PDT (odds ratio, 0.22 (95\% Cl, 0.11 to 0.41 $(P<0.00001))$ and rest of the other complications did not meet statistical significance.

As per the retrospective analysis of the studies, ${ }^{82,83,84,85,86}$ all concluded that PDT and ST are equally safe without any difference in the rate of major complications. PDT had higher peri-procedural complications like false passage whereas ST had higher stomal infection.

As per the DISSECT study, ${ }^{3}$ PDT had marginally higher incidence of intra-procedural minor bleeding and desaturation but ST had higher incidence of major complications like major bleeding, hypotension, need for bronchoalveolar lavage (BAL) and even death.

\section{Recommendation}

The incidence of complications is similar between ST and PDT except for a higher incidence of stomal infection and a bigger scar with ST (I B)

\section{Does ST results in cost reduction for ICU patients as compared to PDT?}

The data on this topic is only available from international studies and is presented only in US dollars. In the RCT by Freeman et al, ${ }^{59}$ PDT had less equipment charges (PDT, \$688 \pm 103 vs. ST, \$1,526 \pm $87, p<0.0001)$ and professional charges as compared to ST (PDT, $\$ 880 \pm 54$ vs. ST, $\$ 1,647 \pm 50 ; p<0.0001)$ and hence overall PDT was cheaper than ST (PDT, \$1,569 $\pm \$ 157$ vs. ST, \$3,172 $\pm \$ 114$ ). Similar findings were present in the RCT by Heikkinen et al $^{62}$ and they concluded that PDT was having a cost beneficial advantage over ST (PDT mean cost \$161 [SD, 10.4; range, \$159-\$219], ST mean cost \$357 [SD, \$74; range, \$239-\$599], $p<0.001)$. Contrary to the literature available, the RCT by Massick et al ${ }^{64}$ revealed that cost of bedside ST was less than PDT by roughly $\$ 436$. This inference was probably due to the procedure being conducted at bedside rather than operation theatre.

A meta-analysis ${ }^{56}$ involving four studies ${ }^{59,62,64,70}$ favored PDT over ST as the cost efficient technique without any increased risk of complications ( $\$ 456.61$ USD less with PDT).

The retrospective data analysis ${ }^{82}$ in cardiac surgery patients who underwent tracheostomy, PDT was found to have significant cost saving potential in terms of decreased ICU days and decrease resource utilization. In another retrospective study, ${ }^{86}$ PDT was found to have significant cost saving potential specifically in resource constraint conditions ( $p<0.0001)$.

As per the DISSECT study, ${ }^{3}$ cost of PDT is much lower than ST in India with an average cost difference of Rs 13104 between the two procedures $(p<0.05)$.

\section{Recommendation}

PDT is more cost effective as compared to ST performed in operation theatre in critically ill patients $(2 \mathrm{~A})$

\section{PDT TECHNIQUE}

Does any technique of PDT results in lower complications in critically ill patients?

RCT by Kost et $\mathrm{al}^{87}$ and Johnson et $\mathrm{l}^{88}$ compared Ciaglia percutaneous tracheostomy multiple dilator vs Ciaglia Blue Rhino Single dilator kit. There were no major differences in complications between the two techniques except the association found between the experience and the chances of complication. It was more with multiple dilator technique $(p<0.0001)$. The other observation was that single dilator technique was faster (6:01 \pm 3:03 mins vs 10:01 $\pm 4: 26$ mins, $p<0.0006$ )

In a cohort study ${ }^{89}$ with long term follow up of Griggs technique, it was found that one third of the patients had tracheal dilatation even after decannulation which was not present after Ciaglia technique in other studies. In another RCT comparing Ciaglia single dilator with Griggs technique, it was found that major complication rate was 4.4 times higher with Griggs technique. Similarly, postoperative complications were less with Ciaglia technique ( $2 \%$ vs $25 \%, p=0.023)^{90}$ and there was a risk of over dilatation with Griggs technique. ${ }^{91}$ In a biomechanical animal study ${ }^{92}$ comparing Ciaglia and Griggs technique, it was concluded that Ciaglia technique required almost $50 \%$ more energy to perform a PDT $(p<0.0001)$.

The systematic review in $2014^{93}$ compared various techniques of PDT. The techniques compared were Ciaglia Multiple dilator vs Ciaglia Blue Rhino, ${ }^{88,94}$ Ciaglia Blue Rhino vs Ciaglia Balloon Dilator, ${ }^{95}$ Ciaglia Blue Rhino vs Griggs Dilating forceps, ${ }^{91,96-98}$ Ciaglia Multiple Dilator vs PercuTwist, ${ }^{99}$ Ciaglia Blue Rhino vs PercuTwist, ${ }^{100}$ Ciaglia Multiple Dilator vs Griggs, ${ }^{90,101,103}$ Ciaglia Multple Dilator vs PercuTwist vs Griggs, ${ }^{102}$ Griggs vs Fantoni, ${ }^{104}$ Griggs vs PercuTwist. ${ }^{105}$ Among all the techniques, it is impossible to decide which is better but Blue Rhino method is less difficult and preferred by physicians. ${ }^{93}$

In DISSECT Study, ${ }^{3}$ single dilator technique was the most preferred technique followed by Griggs technique and then multiple dilator ( $60.4 \%$ vs $28.7 \%$ vs $11 \%$ respectively)

\section{Recommendation}

- All the techniques of PDT do not differ in the incidence of complication rates (2 B)

- The single dilator technique may be used by less experienced operators (UPP)

\section{Does the use of Fiberoptic Bronchoscope (FOB) while performing PDT reduces the complication rate?}

There have been very few RCTs studying the direct relationship of bronchoscopy guided PDT and the incidence of complications. In the earlier studies ${ }^{78,87,106}$ it was found that bronchoscopic guidance reduces the risk of complications and is safe and cost effective but the recent studies ${ }^{107,108}$ have demonstrated that PDT can be safely performed even without bronchoscopic guidance and avoid delays due to non-availability of bronchoscope. The most common complication mentioned in all the studies was desaturation during the procedure.

Most of the data available is from retrospective studies. The studies $^{109-115}$ compared PDT with and without bronchoscopy in various clinical subset and all of them concluded that PDT can be safely performed even without the aid of bronchoscope 
without any increase in complications and it is not mandatory to do bronchoscopy guided PDT. The complications studied were bleeding, desaturation and false passage. Similarly, in the metaanalysis by Putensen et $\mathrm{al}^{81}$ there was no difference in procedural bleeding with or without bronchoscope. In DISSECT study, $28.1 \%$ PDT were done with the guidance of FOB.

\section{Recommendation}

Fiberoptic bronchoscope may be used, whenever available to aid PDT although it does not reduce the rate of complications. (UPP)

\section{Does the use of real-time ultrasound (US) of neck while performing PDT reduces the complication rate?}

Yavuz et al ${ }^{116}$ compared US guided neck anatomy evaluation vs clinical judgement and found that perioperative complication was lower with US group although not statistically significant (7.8\% vs $15 \%)$. The puncture attempts were also lower with US group (3.9\% vs $13.6 \%, p=0.003)$. In another $\mathrm{RCT}^{117}$ Fiberoptic bronchoscopy guided PDT was compared with US guided PDT. The mean hemorrhage ratio and the procedure time was lower with US PDT $(p<0.05)$. Similarly, the Trachus trial ${ }^{118}$ compared US PDT vs FOB PDT and found no difference in complication rate. Mahmoud et $\mathrm{al}^{119}$ compared US with FOB with no guidance. The landmark technique was associated with higher complications as compared to the guidance methods. Comparing US with FOB, did not result in any major statistically significant difference. In another $\mathrm{RCT}^{120}$ comparing landmark technique with US PDT, first pass puncture success rate was higher with US PDT ( $87 \%$ vs $58 \%, \mathrm{Cl} 1.03$ to 2.17 , $p=0.028)$. The procedural complication rate was not statistically significant ( $22 \%$ vs $37 \%, \mathrm{Cl} 0.23$ to $1.47, p=0.24)$

In the two retrospective studies, ${ }^{121,122}$ it was found that real time US guided PDT was not associated with any complications and reduced the number of puncture attempts as compared to the landmark technique. In another retrospective comparative analysis ${ }^{121}$ between real time US PDT and FOB PDT in obese patients, US group had short operating time (mean \pm SD, $12.8 \pm 4.8$ vs 16.2 \pm 4.4 minutes; $P=0.026)$, fewer punctures $(P=0.011)$ and less hemorrhagic complications ( $2.1 \pm 4.6$ versus $16.8 \pm 4.3 \mathrm{~mL} ; P=0.009$ ).

In the review on US PDT, ${ }^{124}$ the studies included revealed that US helps in defining the landmarks for tracheostomy, ${ }^{125,126}$ in identifying vulnerable structures like blood vessels and thyroid gland $^{126-128}$ choosing an appropriate location for puncture. ${ }^{129-134}$ In one of the study in neurocritical care over a 8-year period, it was found that the odds of having an adverse outcome was significantly low with US group (odds ratio $=0.08 ; 95 \%$ confidence interval, 0.009 to $0.811 ; P=0.032)^{135}$

As per the data from DISSECT study, ${ }^{3}$ US was used in $38.6 \%$ cases of PDT for evaluation of neck anatomy and to identify the puncture point.

\section{Recommendation}

- Use of real-time ultrasound could identify correct position of puncture, decrease the number of puncture attempts and intraprocedural hemorrhage. (2 B)

- Whenever available, ultrasound should be used to scan the neck to identify the anatomy prior to needle puncture (UPP)

- PDT should be performed under real-time ultrasound guidance whenever expertise is available (UPP)

\section{EXPERIENCE}

Is there any minimum number of tracheostomies required to safely and independently perform the procedure?

Although no major trials are available which have concluded on how many tracheostomies will give sufficient experience to perform the procedure safely but still few observational and prospective analysis have provided some insights. In 2000, Massick et al, ${ }^{136}$ tried to study the learning curve for PDT and the incidence of complications. He concluded that perioperative and late complications were higher in first 20 PDTs, more so in patients with altered or difficult anatomy. They proposed that early experience should be gained in a controlled environment. In the RCT by Nates et al, ${ }^{90}$ they compared two techniques of PDT. They defined senior operator as one who has done $>6$ tracheostomies. They could not find any major difference in complication rates of experienced or inexperienced operators but they concluded that their study was not meant to define the minimum number of tracheostomies required to become a senior operator. ERS/ATS ${ }^{137}$ recommends that the trainee should perform atleast 5-10 PDTs under supervision before performing the procedure independently. They also recommended that the operator should continue to perform atleast 10 PDT /year to maintain the expertise. Similarly, as per the American College of Chest Physicians, ${ }^{138}$ the minimum number of tracheostomies under supervision should be atleast 20 and thereafter the operator should continue doing atleast 10 tracheostomies/year to maintain expertise.

In the DISSECT Study, ${ }^{3}$ most of the tracheostomies were performed by experienced operators having done more than 25 tracheostomies (87.4\%).

\section{Recommendation}

The minimum number of supervised PDT may be atleast 10 to do the procedure independently (UPP)

\section{Is there an appropriate specialist required to perform tracheostomy?}

In 2006, ${ }^{139}$ a questionnaire-based survey was carried out to study the practices of medical intensivists regarding tracheostomy in India. It was found that $57.4 \%$ were anesthesiologist, $7.4 \%$ were pulmonologist and $35.2 \%$ were from medicine background. Almost $90 \%$ tracheostomies performed were PDT. The surgical tracheostomies were performed by ENT specialist. There was no difference in complication rates.

All other data on this topic is retrospective in nature. Klein et $\mathrm{al}^{4}$ and Seder et $\mathrm{al}^{140}$ compared PDT performed by ENT surgeon and intensivist. They concluded that PDT performed by intensivist was equally safe and also reduced delay by avoiding OT waiting time. A similar kind of retrospective analysis was done by Yarmus et $\mathrm{al}^{141}$ where they compared PDT being done by the surgical team vs interventional pulmonologist. They found no difference in complications in either group except a decrease in delay from the decision of doing the tracheostomy to performing the procedure in the pulmonologist group. In an another retrospective data analysis $^{142}$ on physician intensivist performing tracheostomy, it was found that trained physicians working as intensivist can safely perform PDT without an increased incidence of complications. 
As per the data from DISSECT study, ${ }^{3}$ most of the tracheostomies were performed by the intensivist (53.8\%), followed by surgeons (17\%), followed by trainees who were mainly anesthesiologist posted in ICU (13.8\%) and then interventional pulmonologist (0.8\%).

\section{Recommendation}

Any intensivist, proficient in airway management can perform PDT (UPP)

\section{Special Conditions \\ Can PDT be safely performed in Coagulopathic patients?}

In the prospective data collection by Beiderlinden et al., ${ }^{143}$ 137 patients out of 415 had coagulopathy like platelet count $<50,000 / \mathrm{L}$, aPTT $>50$ s or PT $>50 \%$ normal values. They found no difference in bleeding episodes between coagulopathy and noncoagulopathic patients. Auzinger et al. ${ }^{144}$ prospectively collected data of PDT in liver ICU and did not find any increased incidence of bleeding related complications. An abstract by Patel et al. ${ }^{145}$ also concluded that there was no significant increase in respiratory and hemodynamic complications in patients with coagulopathy. In the retrospective single center cohort study, ${ }_{1}^{146}$ patients who underwent PDT were divided into high risk and low risk based on coagulation parameters. There was no change in bleeding complications between the two groups, although the mortality was more in high risk group but unrelated to tracheostomy. Pasin et al. ${ }^{147}$ and Luserbrink et al. ${ }^{148}$ found no increase in bleeding complications in patients on anticoagulants and antiplatelets while undergoing PDT. Whereas Huang et al. ${ }^{149}$ concluded that antiplatelets and anticoagulants increases the risk of bleeding.

\section{Recommendation}

- PDT can be safely performed in coagulopathic patients after appropriate correction of deranged coagulation (UPP)

- Use of FOB \&/or real-time ultrasound can reduce complications in coagulopathic patients (UPP)

- Newer Oral anticoagulants (NOACs) and antiplatelets agents may be stopped, if feasible, before performing tracheostomy (UPP)

\section{Can PDT be safely performed in Morbidly Obese patients?}

Alhajhusain ${ }^{52}$ et al conducted a retrospective analysis of morbidly obese patients who had undergone PDT and could not find any increase in incidence of complications. In the prospective study by Aldawood et al, ${ }^{150} 50$ PDT were performed in obese patients out of total of 227 PDT. There was no difference in incidence of minor complications except in 3 patients where procedure had to be abandoned but none of the complications resulted in death. The use of FOB was higher in obese patients. Guinot et al ${ }^{151}$ conducted PDT under ultrasound guidance and found no difference in incidence of complications in obese and non-obese population ( $35 \%$ vs $33 \%, p=0.92$ ). They concluded that obesity may not constitute a contraindication for US guided PDT. Similarly, in two other studies ${ }^{152,153}$ comparing PDT in obese with non-obese, it was found that incidence of complications was similar in both groups $(p=0.343)$ and PDT can be safely performed in obese patients.

\section{Recommendation}

Use of real-time ultrasound can increase the safety of performing PDT in obese patients (UPP)

\section{ConCLUSION}

The scope of this document is for intensivist and medical practitioners dealing with critically ill patients. PDT is the most preferred technique of performing tracheostomy in critically ill patients and single dilator technique is the one with maximum experience. The timing of tracheostomy does not affect incidence of VAP or mortality but increases VFD and leads to cost saving. Both bronchoscopy and/or ultrasound guidance can be used to perform PDT but the preference now is tilting towards US due to noninferiority to FOB and cost effectiveness. PDT has a learning curve and atleast 10 assisted PDT must be done under supervision before performing the procedure independently. These recommendations have taken into account certain points mentioned in other international guidelines available on the tracheostomy. ${ }^{154-157}$

\section{References}

1. Pratt LW, Ferlito A, Rinaldo A. Tracheotomy: historical review. Laryngoscope 2008;118:1597-1606.

2. Mehta AB, Syeda SN, Bajpayee L, Cooke CR, Walkey AJ, Wiener RS. Trends in tracheostomy for mechanically ventilated patients in the United States, 1993-2012. Am J Respir Crit Care Med 2015;192:446-454.

3. DIlatational percutaneous vs Surgical tracheoStomy in intEnsive Care uni]: A practice pattern observational multicenter study (DISSECT). (Personal communication)

4. Guyatt GH, Oxman AD, Kunz R, Atkins D, Brozek J, Vist G, et al. GRADE guidelines: 2. Framing the question and deciding on important outcomes. Journal of clinical epidemiology 2011;64:395-400.

5. Klein M, Agassi R, Shapira AR, Kaplan DM, Koiffman L, Weksler N. Can intensive care physicians safely perform percutaneous dilatational tracheostomy? An analysis 207 cases. The Israel Medical Association journal: IMAJ 2007;9:717-719.

6. Ben-Nun A, Altman E, Best LA. Extended indications for percutaneous tracheostomy. Ann Thorac Surg 2005;80:1276-1279.

7. Byhahn C, Lischke V, Meininger D, Halbig S, Westphal K. Peri-operative complications during percutaneous tracheostomy in obese patients. Anaesthesia 2005;60(1):12-15.

8. Mansharamani NG, Koziel H, Garland R, LoCicero III J, Critchlow J, Ernst A. Safety of bedside percutaneous dilatational tracheostomy in obese patients in the ICU. Chest 2000;117:1426-1429.

9. Kluge S, Meyer A, Kuhnelt P, Baumann HJ, Kreymann G. Percutaneous tracheostomy is safe in patients severe thrombocytopenia. Chest 2004;126:547-551.

10. Kumar PG, Govil D, Patel SJ, KN J, Gupta S, Srinivasan S, et al. Percutaneous Tracheostomy under real-time ultrasound guidance in coagulopathic patients: A Single Centre Experience (In press IJCCM).

11. Cheung NH, Napolitano LM. Tracheostomy: Epidemiology, indications, timing, technique, and outcomes. Respir Care 2014;59(6):895-919.

12. Griffiths J, Barber VS, Morgan L, Young JD. Systematic review and metaanalysis of studies of the timing of tracheostomy in adult patients undergoing artificial ventilation. BMJ 2005;330(7502):1243.

13. Rumbak MJ, Newton M, Truncale T, Schwartz SW, Adams JW, Hazard PB. A prospective, randomized, study comparing early percutaneous dilatational tracheostomy to prolonged translaryngeal intubation (delayed tracheostomy) in critically ill medical patients. Crit Care Med 2004;32(8):1689-1694.

14. Rodriguez JL, Steinberg SM, Luchetti FA, Gibbons KJ, Taheri PA, Flint LM. Early tracheostomy for primary airway management in the surgical critical care setting. Surgery 1990;108(4):655-659. 
15. Saffle JR, Morris SE, Edelman L. Early tracheostomy does not improve outcome in burn patients. J Burn Care Rehabil 2002;23(6):431-438.

16. Bouderka MA, Fakhir B, Bouaggad A, Hmamouchi B, Hamoudi D, Harti A. Early tracheostomy versus prolonged endotracheal intubation in severe head injury. J Trauma 2004;57(2):251-254.

17. Terragni PP, Antonelli M, Fumagalli R, Faggiano C, Berardino $M$, Pallavicini $F B$, et al. Early vs late tracheotomy for prevention of pneumonia in mechanically ventilated adult ICU patients: a randomized controlled trial. JAMA 2010;303(15):1483-1489.

18. Wang F, Wu Y, Bo L, Lou J, Zhu J, Chen F, et al. The timing of tracheotomy in critically ill patients undergoing mechanical ventilation: a systematic review and meta-analysis of randomized con-trolled trials. Chest 2011;140(6):1456-1465.

19. Barquist ES, Amortegui J, Hallal A, Giannotti G, Whinney R, Alzamel H, MacLeod J. Tracheostomy in ventilator dependent trauma patients: a prospective, randomized intention-to-treat study. J Trauma 2006;60(1):91-97.

20. Blot F, Similowski T, Trouillet JL, Chardon P, Korach JM, Costa MA, et al. Early tracheotomy versus prolonged endotracheal intubation in unselected severely ill ICU patients. Intensive Care Med 2008;34(10):1779-1787.

21. Trouillet JL, Luyt CE, Guiguet M, Ouattara A, Vaissier E, Makri R, et al. Early percutaneous tracheotomy versus prolonged intubation of mechanically ventilated patients after cardiac surgery: a randomized trial. Ann Intern Med 2011;154(6):373-383.

22. Shan L, Hao P, Xu F, Chen Y.-G. Benefits of early tracheotomy: A meta-analysis based on 6 observational studies. Respir Care 2013;58(11):1856-1862.

23. Moller MG, Slaikeu JD, Bonelli P, Davis AT, Hoogeboom JE, Bonnell BW. Early tracheostomy versus late tracheostomy in the surgical intensive care unit. Am J Surg 2005;189(3):293-296.

24. Zagli G, Linden M, Spina R, Bonizzoli M, Cianchi G, Anichini V, et al. Early tracheostomy in intensive care unit: a retrospective study of 506 cases of video-guided Ciaglia Blue Rhino tracheostomies. J Trauma 2010;68(2):367-372.

25. Tong CC, Kleinberger AJ, Paolino J, Altman KW. Tracheotomy timing and outcomes in the critically ill. Otolaryngol Head Neck Surg 2012;147(1):44-51.

26. Meng L, Wang C, Li J, Zhang J. Early vs late tracheostomy in critically ill patients: a systematic review and meta-analysis. Clin Respir J 2016;10:684-692.

27. Mohamed KAE, Mousa AY, EISawy AS, Saleem AM. Early versus late percutaneous tracheostomy in critically ill adult mechanically ventilated patients. Egypt J Chest Dis Tuberc 2014;63(2):443-448.

28. Zirpe KG, Tambe DV, Deshmukh AM, Gurav SK. The impact of early tracheostomy in neurotrauma patients: A retrospective study. Indian J Crit Care Med 2017;21:6-10.

29. Young D, Harrison DA, Cuthbertson BH, Rowan K. TracMan Collaborators. Effect of early vs late tracheostomy placement on survival in patients receiving mechanical ventilation: the TracMan randomized trial. JAMA. 2013;309(20):2121-2129.

30. Devarajan J, Vydyanathan A, Meng Xu, Murthy MS, McCurry KR, Sessler $\mathrm{DI}$, et al. Early tracheostomy is associated with improved outcomes in patients who require prolonged mechanical ventilation after cardiac surgery. J Am Coll Surg 2012;214:1008-1016.

31. Arabi Y, Haddad S, Shirawi N, AI SA. Early tracheostomy in intensive care trauma patients improves resource utilization: a cohort study and literature review. Crit Care 2004;8(5):R347-R352.

32. Hosokawa K, Nishimura M, Egi M, Vincent JL. Timing of tracheotomy in ICU patients: a systematic review of randomized controlled trials. Critical Care 2015;19:424.

33. Diaz-Prieto A, Mateu A, Gorriz M, Ortiga B, Truchero C, Sampietro N, et al. A randomized clinical trial for the timing of tracheotomy in critically ill patients: factors precluding inclusion in a single center study. Crit Care. 2014;18(5):585.

34. Zheng Y, Sui F, Chen XK, Zhang GC, Wang XW, Zhao S, et al. Early versus late percutaneous dilatational tracheostomy in critically ill patients anticipated requiring prolonged mechanical ventilation. Chin Med J. 2012;125(11):1925-1930.

35. T. Szakmany, P. Russell, A. R. Wilkes and J. E. Hall. Effect of early tracheostomy on resource utilization and clinical outcomes in critically ill patients: meta-analysis of randomized controlled trials. British Journal of Anaesthesia 2015;114(3):396-405.

36. Saboori M, Esmaili Taramsari M, Hosseini B. The effects of early tracheostomy on outcomes of patients with severe head injury. J Isfahan Med Sch 2009;27:211-216

37. Bosel J, Schiller P, Hook Y, Andes M, Neumann JO, Poli S, et al. Strokerelated early tracheostomy versus prolonged orotracheal intubation in neurocritical care trial (SETPOINT): a randomized pilot trial. Stroke 2013;44:21-28.

38. Andriolo BN, Andriolo RB, Saconato H, Atallah ÁN, Valente O. Early versus late tracheostomy for critically ill patients. Cochrane Database Syst Rev. 2015;1:CD007271.

39. Qureshi MSS, Shad ZS, Shoaib F, Munawar K, Saeed ML, Hussain SW, et al. Early Versus Late Tracheostomy After Decompressive Craniectomy. Cureus. 2018;10(12):e3699.

40. Roushdy MM, Abdel-Ghaffar HS, Saleh AE. Does early tracheostomy affect the duration of mechanical ventilation in patients with severe traumatic head injuries? The Egyptian Journal of Otolaryngology 2018;34:127-131.

41. Dochi H, Nojima M, Matsumura M, Cammack I, Furuta Y. Effect of early tracheostomy in mechanically ventilated patients. Laryngoscope Investig Otolaryngol. 2019;4(3):292-299.

42. Tai HP, Lee DL, Chen CF, Huang YT. The effect of tracheostomy delay time on outcome of patients with prolonged mechanical ventilation: A STROBE-compliant retrospective cohort study. Medicine (Baltimore). 2019;98(35):e16939.

43. Khammas AH, Dawood MR. Timing of tracheostomy in intensive care unit patients. Int Arch Otorhinolaryngol 2018;22:437-442.

44. Cinotti R, Voicu S, Jaber S, Chousterman B, Paugam-Burtz C, Oueslati $\mathrm{H}$, et al. Tracheostomy and long-term mortality in ICU patients undergoing prolonged mechanical ventilation. PLoS ONE 2019;14(10):e0220399.

45. Koch T, Hecker B, Hecker A, Brenck F, Preuß M, Schmelzer T. Early tracheostomy decreases ventilation time but has no impact on mortality of intensive care patients: a randomized study. Langenbecks Arch Surg 2012;397:1001-1008.

46. Des,er SB. Does Tracheostomy Affect the Mortality and Morbidity Rate After Cardiac Surgery? Journal of Clinical and Experimental Investigations, 2018;9(2):81-86.

47. El-Naggar M, Sadagopan S, Levine H, Kantor H, Collins VJ. Factors influencing choice between tracheostomy and prolonged translaryngeal intubation in acute respiratory failure: a prospective study. Anesth Analg 1976;55:195-201.

48. Sugerman HJ, Wolfe L, Pasquale MD, Rogers FB, O'Malley KF, Knudson M, et al. Multicenter, randomized, prospective trial of early tracheostomy. J Trauma 1997;43:741-747.

49. Siempos II, Ntaidou TK, Filippidis FT, Choi AMK. Effect of early versus late or no tracheostomy on mortality and pneumonia of critically ill patients receiving mechanical ventilation: a systematic review and meta-analysis. Lancet Respir Med 2015;3:150-158.

50. Liu CC, Livingstone D, Dixon E, Dort JC. early versus late tracheostomy: a systematic review and meta-analysis. Head and Neck Surgery 2015;152(2):219-227.

51. Scales DC, Thiruchelvam D, Kiss A, Redelmeier DA. The effect of tracheostomy timing during critical illness on long-term survival. Crit Care Med 2008;36:2547-2557.

52. Alhajhusain A, Ali AW, Najmuddin A, Hussain K, Aqeel M, El-Solh AA. Timing of tracheotomy in mechanically ventilated critically ill morbidly obese patients. Crit Care Res Pract. 2014;2014:840638.

53. Silvester W, Goldsmith D, Uchino S, Bellomo R, Knight S, Seevanayagam S. Percutaneous versus surgical tracheostomy: A randomized controlled study with long-term follow-up. Crit Care Med 2006;34:2145-2152. 
54. Youssef TF, Ahmed MR, Saber A. Percutaneous dilatational versus conventional surgical tracheostomy in intensive care patients. North Am J Med Sci 2011;3:508-512.

55. Gysin C, Dulguerov P, Guyot JP, Perneger TV, Abajo B, Chevrolet JC. Percutaneous Versus Surgical Tracheostomy A Double-Blind Randomized Trial. Ann. Surg. 1999;230(5):708-714.

56. Higgins KM, Punthakee X. Meta-Analysis Comparison of Open Versus Percutaneous Tracheostomy. Laryngoscope, 2007;117:447-454.

57. Antonelli M, Michetti V, Di Palma, Conti G, Pennisi MA, Arcangeli A, et al. Percutaneous translaryngeal versus surgical tracheostomy: $A$ randomized trial with 1-yr double blind follow-up. Crit Care Med 2005;33:1015-1020.

58. Crofts SL, Alzeer A, McGuire GP, Wong DT, Charles D. A comparison of percutaneous and operative tracheostomy in intensive care patients. Can J Anesth 1995;42:775-779.

59. Freeman BD, Isabella K, Cobb JP, Boyle WA 3rd, Schmieg RE Jr, Kolleff $\mathrm{MH}$, et al. A prospective, randomized study comparing percutaneous with surgical tracheostomy in critically ill patients. Crit Care Med 2001;29:926-930

60. Friedman Y, Fildes J, Mizock B, Samuel J, Patel S, Appavu S, et al. Comparison of percutaneous and surgical tracheostomies. Chest 1996;110:480-485.

61. Hazard P, Jones C, Benitone J. Comparative clinical trial of standard operative tracheostomy wit percutaneous tracheostomy. Crit Care Med 1991;19:1018-1024.

62. Heikkinen M, Aarnio P, Hannukainen J. Percutaneous dilatational tracheostomy or conventional surgical tracheostomy? Crit Care Med 2000;28:1399-1402.

63. Holdgaard HO, Pedersen J, Jensen RH, Outzen KE, Midtgaard T, Johansen LV, et al. Percutaneous dilatational tracheostomy versus conventional surgical tracheostomy. Acta Anaesthesiol Scand 1998:42:545-550.

64. Massick DD, Yao S, Powell DM, Griesen D, Hobgood T, Allen JN, et al. Bedside tracheostomy in the intensive care unit: a prospective randomized trial comparing open surgical tracheostomy with endoscopically guided percutaneous dilatational tracheotomy. Laryngoscope 2001;111:494-500.

65. Melloni G, Muttini S, Gallioli G, Carretta A, Cozzi S, Gemma M, et al. Surgical tracheostomy versus percutaneous dilatational tracheostomy: a prospective- randomized study with long-term follow-up. J Cardiovasc Surg 2002;43:113-121.

66. Porter JM, Ivatury RR. Preferred route of tracheostomy, per- cutaneous versus open at the bedside: a randomized, prospective study in the surgical intensive care unit. Am Surg 1999;65:142-146.

67. Raine RI, Michell WL, Ruttman TG, et al. Late outcome after guidewire forceps percutaneous tracheostomy: a prospective, randomized comparison with open surgical tracheostomy [Abstract]. Br J Anaesth 1999;82:168.

68. Sustic A, Krstulovic B, Eskinja N, Zelić M, Ledić D, Turina D. Surgical tracheostomy versus percutaneous dilatational tracheostomy in patients with anterior cervical spine fixation: preliminary report. Spine 2002;27:1942-1945.

69. Tabaee A, Geng E, Lin J, Kakoullis S, McDonald B, Rodriguez H, et al. Impact of neck length on the safety of percutaneous and surgical tracheotomy: a prospective, randomized study. Laryngoscope 2005:115:1685-1690.

70. Wu JJK, Huang MS, Tang GJ, Shih SC, Yang CC, Kao WF, et al. Percutaneous dilatational tracheostomy versus open tracheostomy: a prospective, randomized, controlled trial. J Chin Med Assoc 2003;66:467-473.

71. Johnson-Obaseki S, Veljkovic A, Javidnia H. Complication rates of open surgical versus percutaneous tracheostomy in critically ill patients. Laryngoscope. 2016;126(11):2459-2467.

72. Hasanloei M, Mahoori A, Bazzazi A, Golzari SEJ, Karami T. Percutaneous Dilatational Tracheostomy and Surgically Created Tracheostomy in ICU Patients. J Cardiovasc Thorac Res 2014;6:43-46
73. MacCallum PL, Parnes LS, Sharpe MD, Harris C. Comparison of open, percutaneous, and translaryngeal tracheostomies. Otolaryngol Head Neck Surg 2000;122:686-690.

74. Silvester W, Goldsmith D, Uchino S, Bellomo R, Knight S, Seevanayagam $S$, et al. Percutaneous versus surgical tracheostomy: A randomized controlled study with long-term follow-up. Crit Care Med 2006;34:2145-2152.

75. Stoeckli S, Breitbach T, Schmid S. Clinical and histologic comparison of percutaneous dilatational versus conventional surgical tracheostomy. Laryngoscope 1997;107:1643-1646.

76. Türkmen A, Altan A, Turgut N, Yildirim G, Ersoy A, Koksal C, et al. Comparison of Percutaneous dilatational tracheostomy with surgical tracheostomy. Middle East J Anaesthesiol 2008;19:1055-1067.

77. Youssef T, Ahmed M, Saber A. Percutaneous dilatational versus conventional surgical tracheostomy in intensive care patients. $\mathrm{N} \mathrm{Am}$ J Med Sci 2011;3:508-512.

78. Barba C, Angood P, Kauder D, Latenser B, Martin K, McGonigal MD, et al. Bronchoscopic guidance makes percutaneous tracheostomy a safe, cost-effective, and easy-to-teach procedure. Surgery 1995;118:879_ 883.

79. Delaney A, Bagshaw SM, Nalos M. Percutaneous dilatational tracheostomy versus surgical tracheostomy in critically ill patients: a systematic review and meta-analysis. Critical Care 2006;10:R55.

80. Jong Joon A, Koh Y, Jae Yong C, Ki Man L, Park W, Hong SB, et al. Comparison of clinical efficacy between percutaneous dilatational tracheostomy and surgical tracheostomy. Tuberculosis Respiratory Dis 1998;45:1277-1283.

81. Putensen C, Theuerkauf N, Guenther U, Vargas M, Pelosi P. Percutaneous and surgical tracheostomy in critically ill adult patients: a meta-analysis. Critical Care 2014;18:544.

82. Bacchetta MD, Girardi LN, Southard EJ, Mack CA, Ko W, Tortolani AJ. Comparison of open versus bedside percutaneous dilatational tracheostomy in the cardiothoracic surgical patient: outcomes and financial analysis. Ann Thorac Surg 2005;79:1879-1885.

83. Vargas M, Sutherasan Y, Antonelli M, Brunetti L, Corcione A, Laffey JG. Tracheostomy procedures in the intensive care unit: an international survey. Critical Care 2015;19:291.

84. Cipriano A, Mao ML, Hon HH, Vazquez D, Stawicki SP, Sharpe RP, et al. An overview of complications associated with open and percutaneous tracheostomy procedures. Int J Crit IIIn Inj Sci 2015;5:179-188.

85. Allam MGIM, Eldeek AM. Comparative study between percutaneous dilatation tracheostomy and surgical tracheostomy. Ain-Shams Journal of Anesthesiology 2015; 8(4):505-510.

86. Brotfain E, Koyfman L, Frenkel A, Semyonov M, Peiser JG, HayunMaman $\mathrm{H}$, et al. Bedside percutaneous tracheostomy versus open surgical tracheostomy in non-ICU patients. Crit Care Res Pract. 2014;2014:156814

87. Kost KM. Endoscopic percutaneous dilatational tracheotomy: a prospective evaluation of 500 consecutive cases. Laryngoscope, 2005;115:1-30.

88. Johnson JL, Cheatham ML, Sagraves SG, Block EFJ, Nelson LD. Percutaneous dilatational tracheostomy: A comparison of singleversus multiple-dilator techniques. Crit Care Med 2001;29:1251-1254.

89. Steele AMB, Evans HW, Afaq MA, Robson JM, Dourado J, Tayar R, et al. Long-term follow-up of Griggs percutaneous tracheostomy with spiral CT and questionnaire. Chest 2000;117:1430-1433.

90. Nates JL, Cooper DJ, Myles PS, Scheinkestel CD, Tuxen DV. Percutaneous tracheostomy in critically ill patients: A prospective, randomized comparison of two techniques. Crit Care Med 2000;28:3734 -3739.

91. Ambesh SP, Pandey CK, Srivastava S, Agarwal A, Singh DK. Percutaneous tracheostomy with single dilatation technique: a prospective, randomized comparison of ciaglia blue rhino versus Griggs' guidewire dilating forceps. Anesth Analg 2002;95:1739-1745.

92. Ronen O, Rosin I, Taitelman UZ, Altman E. Comparison of Ciaglia and Griggs percutaneous tracheostomy techniques - a biomechanical animal study. Indian J Crit Care Med 2019;23(6):247-250. 
93. Sanabria A. Which percutaneous tracheostomy method is better? A systematic review. Respir Care 2014;59(11):1660-1670.

94. Byhahn C, Wilke HJ, Halbig S, Lischke V, Westphal K. Percutaneous tracheostomy: Ciaglia Blue Rhino versus the basic Ciaglia technique of percutaneous dilatational tracheostomy. Anesth Analg 2000;91(4):882886.

95. Cianchi G, Zagli G, Bonizzoli M, Batacchi S, Cammelli R, Biondi $S$, et al. Comparison between single-step and balloon dilatational tracheostomy in intensive care unit: a single-centre, randomized con- trolled study. Br J Anaesth 2010;104(6):728-732.

96. Añón JM, Escuela MP, Gómez V, Moreno A, López J, Díaz R, et al. Percutaneous tracheostomy: Ciaglia Blue Rhino versus Griggs' guide wire dilating forceps. A prospective randomized trial. Acta Anaesthesiol Scand 2004;48(4):451-456.

97. Kumar M, Trikha A, Chandralekha. Percutaneous dilatational tracheostomy: Griggs guide wire dilating forceps technique versus ULTRA-perc single-stage dilator-a prospective randomized study. Indian J Crit Care Med 2012;16(2):87-92.

98. Karvandian K, Yousefian M, Khan ZH, Baigmohammadi T, Shabani S. Comparative clinical trial between Ciaglia and Griggs techniques during tracheostomy performed in patients admitted to intensive care unit. Acta Med Iran 2012;50(8):525-529.

99. Birbicer H, Doruk N, Yapici D, Atici S, Altunkan AA, Epozdemir S, et al. Percutaneous tracheostomy: a comparison of PercuTwist and multidilatators techniques. Ann Card Anaesth 2008;11(2):131.

100. Byhahn C, Westphal K, Meininger D, Gürke B, Kessler P, Lischke V. Single-dilator percutaneous tracheostomy: a comparison of PercuTwist and Ciaglia Blue Rhino techniques. Intensive Care Med 2002;28(9):1262-1266.

101. Van Heurn LW, Mastboom WB, Scheeren Cl, Brink PR, Ramsay G. Comparative clinical trial of progressive dilatational and forceps dilatational tracheostomy. Intensive Care Med 2001;27(1):292-295.

102. Yurtseven N, Aydemir B, Karaca P, Aksoy T, Komurcu G, Kurt M, et al. PercuTwist: a new alternative to Griggs and Ciaglia's techniques. Eur J Anaesthesiol 2007;24(6):492-497.

103. Kaiser E, Cantais E, Goutorbe P, Salinier L, Palmier B. Prospective randomized comparison of progressive dilatational vs forceps dilatational percutaneous tracheostomy. Anaesth Intensive Care 2006;34(1):51-54.

104. Cantais E, Kaiser E, Le-Goff Y, Palmier B. Percutaneous tracheostomy: prospective comparison of the translaryngeal technique versus the forceps-dilatational technique in 100 critically ill adults. Crit Care Med 2002;30(4):815-819.

105. Montcriol A, Bordes J, Asencio Y, Prunet B, Lacroix G, Meaudre E. Bedside percutaneous tracheostomy: a prospective randomised comparison of PercuTwist versus Griggs' forceps dilatational tracheostomy. Anaesth Intensive Care 2011;39(2):209-216.

106. Fernandez L, Norwood S, Roettger R, Gass D, Wilkins H. Bedside Percutaneous tracheostomy with bronchoscopic guidance in critically ill patients. Arch Surg 1996;131:129-132.

107. Taha A, Omar AS. Percutaneous dilatational tracheostomy. Is bronchoscopy necessary? A randomized clinical trial. Trends in Anaesthesia and Critical Care 2017;15:20-24.

108. Lima EJ. Percutaneous Tracheostomy without Bronchoscopy a Safe Procedure. J Intensive \& Crit Care 2016;2:2.

109. Hinerman R, Alvarez F, Keller C. A. Outcome of bedside percutaneous tracheostomy with bronchoscopic guidance. Intensive Care Med 2000;26:1850-1856.

110. Paran H, Butnaru G, Hass I, Afanasyv A, Gutman M. Evaluation of a modified percutaneous tracheostomy technique without bronchoscopic guidance. Chest 2004;126:868-871.

111. Jackson LSM, Davis JW, Kaups KL, Sue LP, Wolfe MM, Bilello JF, et al. Percutaneous tracheostomy: to bronch or not to bronch - that is the question. J Trauma. 2011;71:1553-1556.

112. Dennis BM, Eckert MJ, Gunter OL, Morris Jr JA, May AK. Safety of bedside percutaneous tracheostomy in the critically ill: evaluation of more than 3,000 procedures. J Am Coll Surg 2013;216:858e867.
113. Pattnaik SK, Ray B, Sinha S. Griggs percutaneous tracheostomy without bronchoscopic guidance is a safe method: A case series of 300 patients in a tertiary care Intensive Care Unit. Indian J Crit Care Med 2014;18:778-782.

114. Gadkaree SK, Schwartz D, Gerold K, Kim Y. Use of bronchoscopy in percutaneous dilatational tracheostomy. JAMA Otolaryngol Head Neck Surg. 2016;142(2):143-149.

115. Almansoury A, Ali S, Said H. Percutaneous tracheostomy, making it easier. Egyptian Journal of Bronchology 2018;12:405-412.

116. Yavuz A, Yılmaz M, Göya C, Alimoglu E, Kabaalioglu A. Advantages of US in percutaneous dilatational tracheostomy: randomized controlled trial and review of the literature. Radiology. 2014;273(3):927-936.

117. Sarıtaş A, Kurnaz MM. Comparison of bronchoscopy-guided and realtime ultrasound-guided percutaneous dilatational tracheostomy: safety, complications, and effectiveness in critically ill patients. J Intensive Care Med. 2017:885066617705641.

118. Gobatto ALN, Besen BAMP, Tierno PFGMM, Mendes PV, Cadamuro $F$, Joelsons D. Ultrasound-guided percutaneous dilatational tracheostomy versus bronchoscopy-guided percutaneous dilatational tracheostomy in critically ill patients (TRACHUS): a randomized noninferiority controlled trial. Intensive Care Med. 2016;42(3):342-351.

119. Mahmoud IF, Abdelmottaleb NA, El-Shiekh AM, Erwi SM. Guidance for percutaneous tracheostomy: ultrasonography, fiberoptic bronchoscopy, or no guidance at all. Al-Azhar Assiut Medical Journal 2019;17:227-232.

120. Rudas M, Seppelt I, Herkes R, Hislop R, Rajbhandari D, Weisbrodt L. Traditional landmark versus ultrasound guided tracheal puncture during percutaneous dilatational tracheostomy in adult intensive care patients: a randomised controlled trial. Critical Care 2014,18:514.

121. Mitra S, Kapoor D, Srivastava M, Sandhu H. Real-time ultrasound guided percutaneous dilatational tracheostomy in critically ill patients: A step towards safety!. Indian J Crit Care Med 2013;17:367-369.

122. Ravi PR, Vijai MN, ShoucheS. Realtime ultrasound guided percutaneous tracheostomy in emergency setting: the glass ceiling has been broken. Disaster and Mil Med 2017;3:7.

123. Song J, Xuan L, Wu W, Zhu D, Zheng Y. Comparison of percutaneous dilatational tracheostomy guided by ultrasound and bronchoscopy in critically ill obese patients. J Ultrasound Med 2018;37:1061-1069.

124. Alansari M, Alotair $H$, Aseri JA, Elhoseny MA. Use of ultrasound guidance to improve the safety of percutaneous dilatational tracheostomy: a literature review. Critical Care 2015;19:229.

125. Dinsmore J, Heard AM, Green RJ. The use of ultrasound to guide timecritical cannula tracheotomy when anterior neck airway anatomy is unidentifiable. Eur J Anaesthesiol. 2011;28:506-510.

126. Sustic A, Zupan Z, Antoncić I. Ultrasound-guided percutaneous dilatational tracheostomy with laryngeal mask airway control in a morbidly obese patient. J Clin Anesth. 2004;16:121-123.

127. Shlugman D. Acute fatal haemorrhage during percutaneous dilatational tracheostomy. Br J Anaesth. 2003;90:517-520.

128. Sustić A, Zupan Z, Eskinja N, Dirlić A, Bajek G. Ultrasonographically guided percutaneous dilatational tracheostomy after anterior cervical spine fixation. Acta Anaesthesiol Scand. 1999;43:1078-1080.

129. Bertram S, Emshoff R, Norer B. Ultrasonographic anatomy of the anterior neck:implications for tracheostomy. J Oral Maxillofacial Surg. 1995;53:1420-1424.

130. Tremblay LN, Scales DC. Ultrasound-guided tracheostomy - not for the many, but perhaps the few... or the one. Crit Care. 2011;15:147.

131. Hatfield A, Bodenham A. Portable ultrasonic scanning of the anterior neck before percutaneous dilatational tracheostomy. Anaesthesia. 1999;54:660-663.

132. Flint AC, Midde R, Rao VA, Lasman TE, Ho PT. Bedside ultrasound screening for pretracheal vascular structures may minimize the risks of percutaneous dilatational tracheostomy. Neurocrit Care. 2009;11:372-376.

133. Chacko J, Nikahat J, Gagan B, Umesh K, Ramanathan M. Realtime ultrasound-guided percutaneous dilatational tracheostomy. Intensive Care Med. 2012;38:920-921. 
134. Sustic A, Krstulovic B, Eskinja N, Zelic M, Ledic D, Turina D. Surgical tracheostomy versus percutaneous dilatational tracheostomy in patients with anterior cervical spine fixation: preliminary report. Spine (Phila Pa 1976). 2002;27:1942-1945.

135. Rajajee V, Williamson CA, West BT. Impact of real-time ultrasound guidance on complications of percutaneous dilatational tracheostomy: a propensity score analysis. Critical Care 2015;19:198.

136. Massick DD, Powell DM, Price PD, Chang SL, Squires G, Forrest LA, et al. Quantification of the learning curve for percutaneous dilatational tracheotomy. Laryngoscope, 2000;110:222-228.

137. Bolliger CT, Mathur PN, Beamis JF, Becker HD, Cavaliere S, Colt H, et al. ERS/ATS statement on interventional pulmonology. European Respiratory Society/American Thoracic Society. Eur Respir J. 2002;19(2):356-373.

138. Ernst A, Silvestri GA, Johnstone D. Interventional pulmonary procedures: guidelines from the American college of chest physicians. Chest 2003;123;1693-1717.

139. Kumar P, Misra A, Anand R, Shastri BVR, Wadhawan S. Audit of the existing attitudes and practices of the medical intensivists regarding tracheostomy in the ICU's in India. Indian J. Anaesth. 2006;50(4):288294.

140. Seder DB, Lee K, Rahman C, Raghunath NR, Fernandez L, Rincon F, et al. Safety and feasibility of percutaneous tracheostomy performed by neurointensivists. Neurocrit Care 2009;10:264-268.

141. Yarmus L, Pandian V, Gilbert C, Schiavi A, Haider A, Chi A, et al. Safety and efficiency of interventional pulmonologists performing percutaneous tracheostomy. Respiration 2012;84:123-127.

142. Khan AZ, Khan A, Naseem A. Percutaneous tracheostomy by physician intensivists. journal of the college of physicians and surgeons Pakistan 2018;28(3):222-225.

143. M. Beiderlinden, M. Eikermann, N. Lehmann, M. Adamzik, J. Peters. Risk factors associated with bleeding during and after percutaneous dilatational tracheostomy. Anaesthesia, 2007;62:342-346.

144. Auzinger G, O'Callaghan GP, Bernal W, Sizer E, Wendon JA. Percutaneous tracheostomy in patients with severe liver disease and a high incidence of refractory coagulopathy: a prospective trial. Critical Care 2007;11:R110.

145. Patel D, Devulapally K, Islam S. Safety of percutaneous tracheostomy in patients with coagulopathy and high ventilatory demand. Chest. 2009;136:50S.
146. Deppe AC, Kuhn E, Scherner M, Slottosch I, Liakopoulos O. Coagulation disorders do not increase the risk for bleeding during percutaneous dilatational tracheotomy. Thorac Cardiovasc Surg 2013;61:234-239.

147. Pasin L, Frati E, Cabrini L, Giovanni L, Nardelli P, Bove T, et al. Percutaneous tracheostomy in patients on anticoagulants. Ann Card Anaesth 2015;18:329-334.

148. Lüsebrink E, Stark K, Bertlich M, Kupka D, Stremmel C, Scherer C, et al. Safety of percutaneous dilatational tracheotomy in patients on dual antiplatelet therapy and anticoagulation. Crit Care Expl 2019;1:e0050.

149. Huang Y-H, Tseng C.-H., Chan M.-C., Lee B.-J., Lin C.-H., Chang G.-C. Antiplatelet agents and anticoagulants increased the bleeding risk of bedside percutaneous dilatational tracheostomy in critically ill patients, Journal of the Formosan Medical Association, https://doi. org/10.1016/j.jfma.2019.10.014

150. Aldawood AS, Arabi YM, Haddad S. Safety of percutaneous tracheostomy in obese critically ill patients: a prospective cohort study. Anaesth Intensive Care 2008;36:69-73.

151. Guinot PG, Zogheib E, Petiot S, Marienne JP, Guerin AM, Monet P, et al. Ultrasound-guided percutaneous tracheostomy in critically ill obese patients. Critical Care 2012;16:R40.

152. Chambers D, Cloyes R, Adam A, Islam S. Percutaneous tracheostomy in severe obesity: experience at a tertiary care center. Chest. 2013;144:66A.

153. Heyrosa MG, Melniczek DM, Rovito P, Nicholas GG. Percutaneous tracheostomy: a safe procedure in the morbidly obese. J Am Coll Surg 2006;202:618-622.

154. Leyn PD, Bedert L, Delcroix M, Depuydt P, Lauwers G, Sokolov Y, et al. Tracheotomy: clinical review and guidelines. European Journal of Cardio-thoracic Surgery 2007;32:412-421.

155. Madsen KR, Guldager H, Rewers M, Weber SO, Jacobsen KK, White J. Danish guidelines 2015 for percutaneous dilatational tracheostomy in the Intensive Care Unit. Dan Med J 2015;62(3):C5042.

156. Raimondi N, Vial MR, Calleja J, Quintero A, Cortés A, Celis E. Evidencebased guidelines for the use of tracheostomy in critically ill patients. Journal of Critical Care 2017;38:304-318.

157. Trouillet JL, Collange O, Belafia F, Blot F, Capellier G, Cesareo E, et al. Tracheotomy in the intensive care unit: guidelines from a French expert panel. Ann. Intensive Care 2018;8:37. 
${ }^{1}$ Department of Critical Care Medicine, Narayana Superspeciality Hospital, Gurugram, Haryana, India, Phone: 9873240734, e-mail: dr_sachin78@ yahoo.co.in

${ }^{2}$ Department of Critical Care Medicine, Sanjeevan \& MJM Hospital, Pune, Maharashtra, India, Phone: 9822050240, e-mail: subhaldixit@yahoo.com ${ }^{3}$ Department of Pulmonary \& Critical Care Medicine, University of Health Sciences Rohtak, Haryana, India, Phone: 9416051616 , e-mail: dhruvachaudhry@yahoo.co.in

${ }^{4}$ Department of Critical Care, Institute of Critical Care \& Anesthesiology, Medanta The Medicity, Gurugram, Haryana, India, Phone: 9818056688 , e-mail: drdeepak_govil@yahoo.co.in

${ }^{5}$ Intensivist \& Internist, Ahmedabad, Gujarat, India, Phone: 9825013983, e-mail: mishr.c@gmail.com

${ }^{6}$ Department of Critical Care, Virinchi Hospital, Hyderabad, Telangana, India, Phone: 9866343632, e-mail: srinivas3271@gmail.com

${ }^{7}$ Department of Neurocritical Care, Ruby Hall Clinic, Grant Medical Foundation, Pune, Maharashtra, India, Phone: 9822844212, e-mail: kapilzirpe@ gmail.com

${ }^{8}$ Department of Critical Care Medicine, Manipal Hospitals, New Delhi, India, Phone: 9560300723, e-mail: Srinivasan.shrikanth@gmail.com

${ }^{9}$ Department of Organ Transplant Anaesthesia and Critical Care, Amrita Institute of Medical Sciences and Research Centre, Kochi, Kerala, India, Phone: 9496038812, e-mail: zubairumer@gmail.com

${ }^{10}$ Department of Critical Care Medicine, Manipal Hospitals, Bengaluru, Karnataka, India, Phone: 9538895391, e-mail: drvenkateshkv@gmail.com ${ }^{11}$ Department of Neuroanaesthesia and Critical Care, Institute of Neurosciences, Medanta The Medicity, Gurugram, Haryana, India, Phone: 8130245666, e-mail: dr_jayawanchoo@yahoo.co.in

${ }^{12}$ Department of Neurointensive Care, Institute of Neurosciences, Kolkata, West Bengal, India, Phone: 9629392583, e-mail: nilanchal83@gmail. com

${ }^{13}$ Department of Neurocritical Care, Ruby Hall Clinic, Grant Medical Foundation, Pune, Maharashtra, India, Phone: 9860034778, e-mail: kirtisush_ gurav@yahoo.co.in 